\title{
Design, Fabrication and Evaluation of Drug Release Kinetics from Aceclofenac Matrix Tablets using Hydroxypropyl Methyl Cellulose
}

\author{
Abul Kalam Lutful Kabir1, Bishyajit Kumar Biswas ${ }^{2}$ and Abu Shara Shamsur Rouf ${ }^{2}$ \\ ${ }^{1}$ Deparment of Pharmacy, Stamford University Bangladesh, Dhaka-1217, Bangladesh \\ ${ }^{2}$ Department of Pharmaceutical Technology, University of Dhaka, Dhaka-1000, Bangladesh
}

\begin{abstract}
The objective of this study was to develop a sustained release matrix tablet of aceclofenac using hydroxypropyl methylcellulose (HPMC K15M and HPMC K100M CR) in various proportions as release controlling factor by direct compression method. The powders for tableting were evaluated for angle of repose, loose bulk density, tapped bulk density, compressibility index, total porosity and drug content etc. The tablets were subjected to thickness, weight variation test, drug content, hardness, friability and in vitro release studies. The in vitro dissolution study was carried out for 24 hours using United States Pharmacopoeia (USP) 22 paddle-type dissolution apparatus in phosphate buffer ( $\mathrm{pH}$ 7.4). The granules showed satisfactory flow properties, compressibility index and drug content etc. All the tablets complied with pharmacopoeial specifications. The results of dissolution studies indicated that the formulations F-2 and F-3 could extend the drug release up to 24 hours. By comparing the dissolution profiles with the marketed product, it revealed that the formulations exhibited similar drug release profile. From this study, a decrease in release kinetics of the drug was observed when the polymer concentration was increased. Kinetic modeling of in vitro dissolution profiles revealed the drug release mechanism ranges from diffusion controlled or Fickian transport to anomalous type or non-Fickian transport, which was only dependent on the type and amount of polymer used. The drug release followed both diffusion and erosion mechanism in all cases. The drug release from these formulations was satisfactory after 3 months storage in $40^{\circ} \mathrm{C}$ and $75 \% \mathrm{RH}$. Besides, this study explored the optimum concentration and effect of polymer(s) on acelofenac release pattern from the tablet matrix for 24 hour period.
\end{abstract}

Key words: Aceclofenac, sustained release, hydrophillic matrix, HPMC, direct compression.

\section{INTRODUCTION}

Aceclofenac is an orally administered phenyl acetic acid derivatives with effects on a variety of inflammatory mediators. ${ }^{1}$ Aceclofenac contains not less than $99.0 \%$ and not more than the equivalent of 101.0 percent of 2-[[2-[2-[(2, 6-dichlorophenyl) amino] phenyl] acetyl] oxy] acetic acid. It is an effective analgesic and anti-inflammatory agent with a good tolerability profile. Through its analgesic and anti-inflammatory properties, aceclofenac provides symptomatic relief in a variety of painful conditions.

Correspondence to:

Abu Shara Shamsur Rouf

E-mail:rouf321@yahoo.com.

Dhaka Univ. J. Pharm. Sci. 8(1): 23-30, 2009 (June)
A reduction in the stimulated generation of reactive oxygen species, which may play a role in joint damage, was observed after 15 days in these patients. At day $180, \mathrm{O}_{2}$ release was similar to that seen in a group of 41 healthy untreated individuals. The successful treatment of arthritis depends on the maintenance of effective drug concentration level in the body for which a constant and uniform supply of drug is desired. The shorter biological half life (about 4 hours) and the dosage frequency more than one per day make aceclofenac an ideal candidate for sustained release formulations, which reduce the frequency of dose in order to improve patient compliance. $^{2}$ The most common method of 
modulating drug release is to include it in a matrix system. Because of their flexibility, hydrophilic polymer matrix systems are widely used in oral controlled drug delivery to obtain a desirable drug release profile, cost effectiveness, and broad regulatory acceptance. Among the hydrophilic polymers, hydroxypropyl methyl cellulose derivatives are frequently used because of its nontoxic nature, easy compression, swelling properties and accommodation to high levels of drug loading. ${ }^{3}$ Additionally, HPMC is a $\mathrm{pH}$ independent material and hence drug release from hydroxypropyl methyl cellulose matrix formulations is generally independent of processing variables. ${ }^{4,5}$ Oral sustained release dosage form by direct compression technique is a very simple approach in the pharmaceutical arena for its ease, compliance, faster production, avoids hydrolytic or oxidative reactions occurred during processing of dosage forms. Sustained or controlled drug delivery occurs while a drug embedded within a polymer that may be natural or semi-synthetic or synthetic in nature. The polymer is judiciously combined with the drug or other active ingredients in such a way that the active agent is released from the material in a predetermined fashion and released drug at constant rate for desired time period. There are number of techniques applied in the formulation and manufacturing of sustained release dosage form. However, the matrix tablet by direct compression has attracted much attention due to its technological simplicity in comparison with other controlled release systems. ${ }^{6}$

\section{MATERIALS AND METHODS}

Materials. The following materials were used: Aceclofenac (Square pharmaceuticals, Bangladesh); Methocel K15M and Methocel K100M CR (Dow Chemical Company, Midland, MI, USA); Microcrystalline Cellulose (Avicel-101), Polyvinyl Pyrrolidone (Povidone K-30), Colloidal Anhydrous Silica (Aerosil 200) and Magnesium stearate (Hanau Chemicals Ltd., Japan); Solvents and reagents: Potassium dihydrogen phosphate (Merck, Germany); Sodium Hydroxide (Merck, Germany); Equipments:
Single Punch Tablet press (Shanghai-Tianhe Pharmaceutical Machinery Company); UV Spectrophometer (Shimadzu, Japan); Digital pH meter (Hach Company, USA); Electronic Hardness tester (Ereweka, Germany); Tablet Dissolution Tester (Electrolab, India); Sartorius Electronic Balance.

Preparation of tablets. The tablet was prepared by simple blending of active ingredient with polymers, filler, binder, lubricant and flow promoter followed by direct compression method (Table 1). 50 tablets were prepared for each proposed formulation. Properly weighed Methocel, Povidone K-30, Avicel $\mathrm{pH}$ 101, magnesium stearate, aerosil and the active ingredient were then taken in a photo film container and blended in a laboratory designed small drum blender machine for 30 minutes to ensure thorough mixing and phase homogenization.

Table 1. Proposed formulations of aceclofenac SR matrix tablets containing Methocel K15M and Methocel K100M CR

\begin{tabular}{lcccc}
\hline \multirow{2}{*}{ Ingredients (mg) } & \multicolumn{4}{c}{ Formulations } \\
\cline { 2 - 5 } & F-1 & F-2 & F-3 & F-4 \\
\hline Aceclofenac & 200 & 200 & 200 & 200 \\
Methocel K15M CR & 50 & 40 & 30 & 20 \\
Methocel K100M CR & 30 & 40 & 50 & 60 \\
Povidone K-30 & 4 & 4 & 4 & 4 \\
Avicel PH 101 & 120 & 120 & 120 & 120 \\
Aerosil 200 & 2.5 & 2.5 & 2.5 & 2.5 \\
Magnesium Stearate & 3.5 & 3.5 & 3.5 & 3.5 \\
Total weight/Tablet (mg) & 410 & 410 & 410 & 410 \\
\hline
\end{tabular}

Physical evaluation of powders. The powders were evaluated for angle of repose, loose bulk density, tapped bulk density, compressibility index, total porosity, and drug content etc. ${ }^{7}$

Bulk density : $L B D$ (Loose Bulk Density) and $T B D$ (Tapped Bulk Density) were determined by $2 \mathrm{~g}$ of powder from each formula, previously lightly shaken to break any agglomerates formed, was placed into a $10-\mathrm{ml}$ measuring cylinder. After the initial volume was observed, the cylinder was allowed to fall under its own weight onto a hard surface from the height of $2.5 \mathrm{~cm}$ at 2-second intervals. The reading of tapping was continued until 
no further change in volume was noted. Using the following equation $L B D$ and $T B D$ was calculated:

$L B D=$ Weight of the powder / volume of the packing.

$T B D=$ Weight of the powder / Tapping volume of the packing.

Compressibility index: The compressibility index of the granules was determined by Carr's compressibility index:

Carr's index $(\%)=\{(T B D-L B D) \times 100\} / T B D$

Total porosity. Total porosity was determined by measuring the volume occupied by a selected weight of powder $\left(V_{b u l k}\right)$ and the true volume of granules (the space occupied by the powder exclusive of spaces greater than the intermolecular space $(V)$ :

Porosity $(\%)=V_{\text {bulk }}-V / V_{\text {bulk }} \times 100$

Angle of repose. The angle of repose of granules was determined by the funnel method. The accurately weighed granules were taken in a funnel. The height of the funnel was adjusted in such a way that the tip of the funnel just touched the apex of the heap of the granules. The granules were allowed to flow through the funnel freely onto the surface. The diameter of the powder cone was measured and angle of repose was calculated using the following equation.

Angle of Repose $\theta=\tan ^{-1} h / r$

Where, $h=$ Height of the powder cone.

$r=$ Radius of the powder cone.

Drug content. An accurately weighed amount of powdered aceclofenac $(100 \mathrm{mg})$ was extracted with water and the solution was filtered through $0.45-\mu$ membrane filter paper. The absorbance was measured at $275 \mathrm{~nm}$ after suitable dilution.

Physical evaluation of aceclofenac matrix tablet. The prepared tablets were subjected to thickness, weight variation test, hardness, friability, and drug content. ${ }^{7,8}$

In vitro dissolution study. The release study was carried out for 24 hours using USP 22 paddletype dissolution apparatus in buffer $(\mathrm{pH} 7.4)$ at 100 $\mathrm{r} / \mathrm{min}$ maintaining $37 \pm 0.5^{\circ} \mathrm{C}$. A $10 \mathrm{ml}$ samples were collected from each vessel at 1, 2, 4, 6, 8, 10, 12, 16, 20 and 24 hour and spectrophotometrically analyzed for aceclofenac at $275 \mathrm{~nm}$. The withdrawn sample was immediately replaced by equal volume of fresh buffer.

Impurity studies. The related substances present in the tablets were determined by HPLC method.

Stability studies. After determining drug content, the tablets were charged for the accelerated stability studies according to ICH guidelines (40 \pm $2^{\circ} \mathrm{C}$ and $75 \pm 5 \% \mathrm{RH}$ ) for a period of 3 months in stability chambers. The samples were taken out at 30 , 60 and 90 days and evaluated for the drug content, dissolution, related substances and physical parameters like hardness and friability (Table 5).

Process validation. Experimental batches were validated to confirm the accuracy and reproducibility of physical and chemical characteristics. Mixing time was validated by performing content uniformity tests for Aceclofenac in the blend at three stages of the mixing time of one hour i.e., $75 \%, 85 \%$ and $100 \%$ of the mixing time. While compression, hardness, thickness and weight variation was evaluated and data was compared for all three batches. In vitro release profile and assay results were also evaluated and compared with predefined criteria.

Data analysis. To analyze the in vitro release data various kinetic models were used to describe the release kinetics. The zero order rate Eq. (1) describes the systems where the drug release rate is independent of its concentration. The first order Eq. (2) describes the release from system where release rate is concentration dependent. Higuchi (1963) described the release of drugs from insoluble matrix as a square root of time dependent process based on Fickian diffusion Eq. (3). The Hixson-Crowell cube root law Eq. (4) describes the release from systems where there is a change in surface area and diameter of particles or tablets.

$$
C=k_{0} t \ldots \ldots \ldots \ldots \ldots \ldots \ldots \ldots \ldots \ldots
$$

Where, $\mathrm{K}_{0}$ is zero-order rate constant expressed in units of concentration/time and $\mathrm{t}$ is the time.

$$
\log C_{0}-\log C=k t / 2.303 \ldots \ldots \ldots \ldots
$$


Where, $\mathrm{C}_{0}$ is the initial concentration of drug and $\mathrm{K}$ is first order constant.

$$
Q=K t^{1 / 2}
$$

Where, $\mathrm{K}$ is the constant reflecting the design variables of the system.

$$
Q_{0}{ }^{1 / 3}-Q_{t}{ }^{1 / 3}=K_{H C} t \ldots \ldots \ldots \ldots \ldots \ldots \ldots
$$

Where, $Q_{t}$ is the amount of drug released in time $\mathrm{t}, \mathrm{Q}_{0}$ is the initial amount of the drug in tablet and $\mathrm{K}_{\mathrm{HC}}$ is the rate constant for Hixson-Crowell rate equation.

The following plots were made: cumulative \% drug release vs. time (zero order kinetic model); log cumulative of $\%$ drug remaining vs. time (first order kinetic model); cumulative \% drug release vs. square root of time (higuchi model) log cumulative \% drug release vs. log time (korsmeyer model) and cube root of drug \% remaining in matrix vs. time (hixsoncrowell cube root law).

Mechanism of drug release. Korsmeyer et al (1983) derived a simple relationship which described drug release from a polymeric system Eq. (5). To find out the mechanism of drug release, first $60 \%$ drug release data was fitted in Korsmeyer-Peppas model:

$$
M_{t} / M \infty=K t n
$$

Where, $M_{t} / M \infty$ is the fraction of drug released at time $\mathrm{t}, \mathrm{k}$ is the rate constant and $\mathrm{n}$ is the release exponent. The $\mathrm{n}$ value is used to characterize different release mechanisms as given in the following table for cylindrical shaped matrices:

Diffusion exponent and solute release mechanism for cylindrical shape

\begin{tabular}{ll}
\hline Diffusion exponent $(\mathrm{n})$ & Overall solute diffusion mechanism \\
\hline 0.45 & Fickian diffusion \\
$0.45<\mathrm{n}<0.89$ & Anomalous (non-Fickian) diffusion \\
0.89 & Case-II transport \\
$\mathrm{n}>0.89$ & Super case-II transport \\
\hline
\end{tabular}

\section{RESULTS AND DISCUSSION}

In the present study, an attempt has been taken to develop "once daily" sustained release tablets of aceclofenac by direct compression method using Methocel $\mathrm{K} 15 \mathrm{M}$ and $\mathrm{K} 100 \mathrm{M} \quad \mathrm{CR}$ as rate retarding factor (Table 1). Methocel K15M and K100M CR was utilized in the proposed formulations F-1 to F-4 in order to evaluate the amount of polymer required to provide desired release rate for 24 hour period. The powders of proposed formulations (F-1 to F-4) were evaluated for LBD, TBD, compressibility index, total porosity, angle of repose and drug content (Table 2). The results of LBD and TBD ranged from $0.40 \pm 0.03$ to $0.51 \pm 0.02$ and $0.57 \pm 0.03$ to $0.72 \pm$ 0.05 respectively. The results of compressibility index $(\%)$ ranged from $16.25 \pm 0.012$ to $27.14 \pm 0.08$.

Table 2. Properties of granules of aceclofenac and excipients containing Methocel K15M CR and Methocel K100M CR

\begin{tabular}{ccccccc}
\hline Tablets & $\begin{array}{c}\text { Angle of } \\
\text { Repose } \\
\left({ }^{\circ}\right)\end{array}$ & $\begin{array}{c}\text { Loose Bulk } \\
\text { Density (LBD) } \\
(\mathrm{g} / \mathrm{ml})\end{array}$ & $\begin{array}{c}\text { Tapped Bulk } \\
\text { Density (TBD) } \\
(\mathrm{g} / \mathrm{ml})\end{array}$ & $\begin{array}{c}\text { Compressibilty } \\
\text { Index }(\%)\end{array}$ & $\begin{array}{c}\text { Total Porosity } \\
(\%)\end{array}$ & $\begin{array}{c}\text { Drug Content } \\
(\%)\end{array}$ \\
\hline F-1 & $23.15 \pm 0.03$ & $0.50 \pm 0.03$ & $0.59 \pm 0.02$ & $19.25 \pm 0.01$ & $25.45 \pm 0.02$ & $98.45 \pm 0.02$ \\
F-2 & $23.05 \pm 0.01$ & $0.41 \pm 0.01$ & $0.55 \pm 0.03$ & $22.15 \pm 0.02$ & $26.98 \pm 0.05$ & $99.21 \pm 0.06$ \\
F-3 & $20.55 \pm 0.02$ & $0.42 \pm 0.05$ & $0.59 \pm 0.04$ & $26.14 \pm 0.02$ & $23 . .21 \pm 0.3$ & $98.55 \pm 0.02$ \\
F-4 & $21.25 \pm 0.04$ & $0.47 \pm 0.03$ & $0.69 \pm 0.05$ & $27.00 \pm 0.04$ & $25.36 \pm 0.12$ & $99.40 \pm 0.03$ \\
\hline
\end{tabular}

Table 3. Properties of aceclofenac matrix tablets containing Methocel K15M CR and Methocel K100M CR

\begin{tabular}{cccccc}
\hline Tablets & $\begin{array}{c}\text { Thickness } \\
(\mathrm{mm})\end{array}$ & $\begin{array}{c}\text { Weight } \\
\text { Variation }(\%)\end{array}$ & $\begin{array}{c}\text { Drug Content } \\
(\%)\end{array}$ & $\begin{array}{c}\text { Hardness } \\
\left(\mathrm{Kg} / \mathrm{cm}^{2}\right)\end{array}$ & $\begin{array}{c}\text { Friability } \\
(\%)\end{array}$ \\
F-1 & $4.15 \pm 0.02$ & $1.50 \pm 0.02$ & $98.07 \pm 0.05$ & $6.50 \pm 0.03$ & $0.25 \pm 0.01$ \\
F-2 & $4.08 \pm 0.03$ & $2.20 \pm 0.02$ & $96.03 \pm 0.05$ & $6.02 \pm 0.03$ & $0.50 \pm 0.01$ \\
F-3 & $4.75 \pm 0.03$ & $4.20 \pm 0.03$ & $98.07 \pm 0.05$ & $6.50 \pm 0.03$ & $0.25 \pm 0.01$ \\
F-4 & $4.52 \pm 0.02$ & $2.75 \pm 0.01$ & $102.65 \pm 0.10$ & $5.00 \pm 0.02$ & $0.33 \pm 0.01$ \\
\hline
\end{tabular}


Table 4. Release parameters of aceclofenac sustained release tablets

\begin{tabular}{ccccccccccc}
\hline \multirow{2}{*}{$\begin{array}{c}\text { Formul } \\
\text { ation }\end{array}$} & \multicolumn{2}{c}{ Zero order } & \multicolumn{2}{c}{ Higuchi } & \multicolumn{2}{c}{ First order } & \multicolumn{2}{c}{ Korsmeyer-Peppas } & \multicolumn{2}{c}{ Hixson- Crowell } \\
\cline { 2 - 11 } & $\mathrm{K}_{0}$ & $\mathrm{R}^{2}$ & $\mathrm{~K}_{\mathrm{h}}$ & $\mathrm{R}^{2}$ & $\mathrm{~K}_{1}$ & $\mathrm{R}^{2}$ & $\mathrm{n}$ & $\mathrm{R}^{2}$ & $\mathrm{~K}_{\mathrm{HC}}$ & $\mathrm{R}^{2}$ \\
\hline F-1 & 4.05 & 0.91 & 21.99 & 0.99 & -0.070 & 0.90 & 0.692 & 0.98 & -0.134 & 0.61 \\
F-2 & 4.03 & 0.92 & 21.77 & 0.99 & -0.063 & 0.94 & 0.693 & 0.99 & -0.133 & 0.62 \\
F-3 & 4.03 & 0.93 & 21.73 & 0.99 & -0.061 & 0.94 & 0.693 & 0.99 & -0.134 & 0.63 \\
F-4 & 4.02 & 0.93 & 21.07 & 0.99 & -0.061 & 0.95 & 0.692 & 0.98 & -0.132 & 0.63 \\
\hline
\end{tabular}

Table 5. Stability study data of aceclofenac matrix tablets

\begin{tabular}{clllll}
\hline \multicolumn{1}{c}{ Properties } & & \multicolumn{3}{c}{ Result } & Specifications \\
\cline { 3 - 5 } & & After 1M & After 2M & After 3M & \\
\hline Drug Content (\%) & & 98.8 & 97.8 & 97.2 & $95 \%-105 \%$ \\
\multirow{2}{*}{ Impurities (\%) } & Diclofenac & 0.69 & 1.23 & 2.35 & NMT 3.5\% \\
& Others & 0.21 & 0.29 & 0.41 & NMT 0.5\% \\
& After 2 hrs & 29.45 & 25.75 & 28.35 & $15 \%-35 \%$ \\
Dissolution (\%) & After 4 hrs & 57.03 & 49.23 & 51.90 & $30 \%-60 \%$ \\
& After 8 hrs & 94.32 & 89.81 & 89.32 & NLT 75\% \\
Hardness (kg/cm $\left.{ }^{2}\right)$ & & $9.35-11.25$ & $8.56-10.54$ & $8.25-9.35$ & $(8.0-14) \mathrm{kg} / \mathrm{cm}^{2}$ \\
Loss on drying (\%) & & 3.85 & 4.26 & 4.73 & NMT 5\% \\
\hline
\end{tabular}

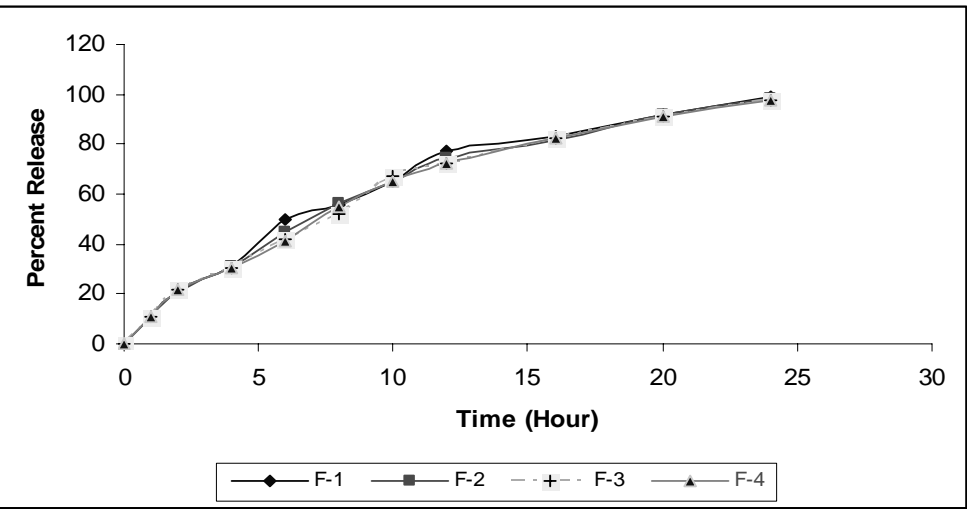

Figure 1. Zero order plot of release kinetics of aceclofenac SR tablets

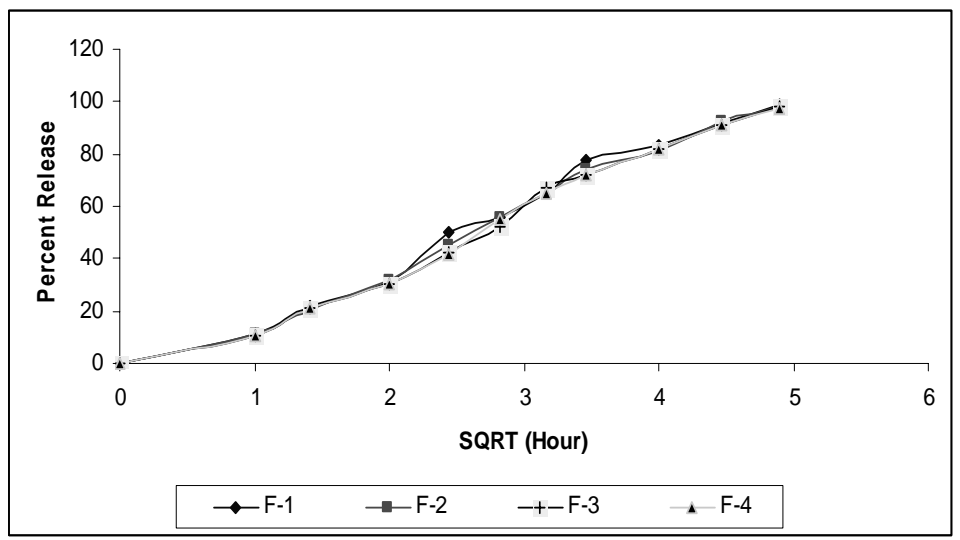

Figure 2. Higuchi plot of release kinetics of aceclofenac SR tablets. 
The results of angle of repose ranged from $20.55 \pm$ 0.02 to $25.15 \pm 0.11\left(^{\circ}\right)$. The percentage porosity values of the granules ranged from $21.0 \pm 0.01$ to $27.25 \pm 0.06 \%$ indicating that the packing of the granules may range from close to loose packing and also further confirming that the particles are not of greatly different sizes. The drug content in a weighed amount of granules of all formulations ranged from $97.55 \pm 0.08$ to $98.45 \pm 0.04 \%$. All these results indicate that the granules possess satisfactory flow properties, compressibility and drug content. The tablets of the proposed formulations (F-1 - F-4) were subjected to various evaluation tests like thickness, hardness, weight variation test and friability (Table 3 ). The thickness of the tablets ranged from $4.05 \pm$ 0.10 to $4.88 \pm 0.03 \mathrm{~mm}$. The hardness and percentage friability of the tablets of all the formulations ranged from $5.0 \pm 0.02$ to $8.1 \pm 0.04 \mathrm{~kg} / \mathrm{cm}^{2}$ and $0.05 \pm 0.04$ to $0.50 \pm 0.01 \%$, respectively. The average percentage deviation of 20 tablets of each formula was less than $\pm 5 \%$. Drug content among different batches of tablets ranged from $96.03 \pm 0.05$ to 102.65 $\pm 0.02 \%$. In a weight variation test, the pharmacopeial limit for the percentage deviation for tablets was $\pm 0.5 \%$. Good uniformity in drug content

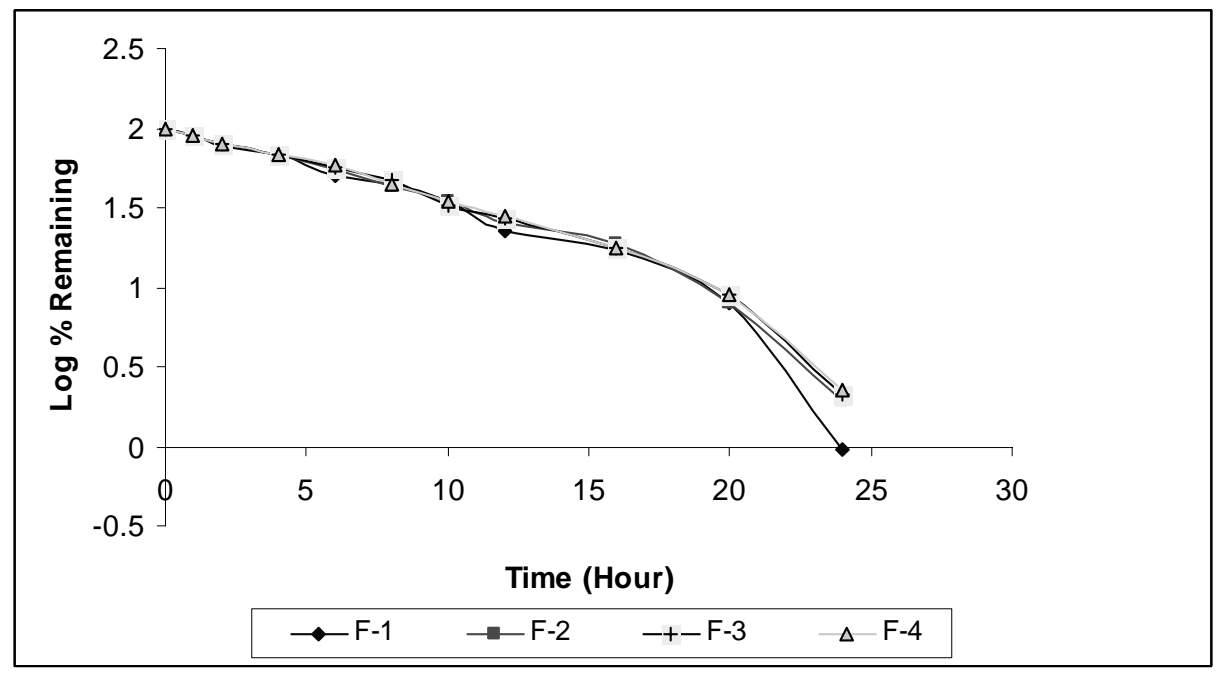

Figure 3. First order plot of release kinetics of aceclofenac SR tablets

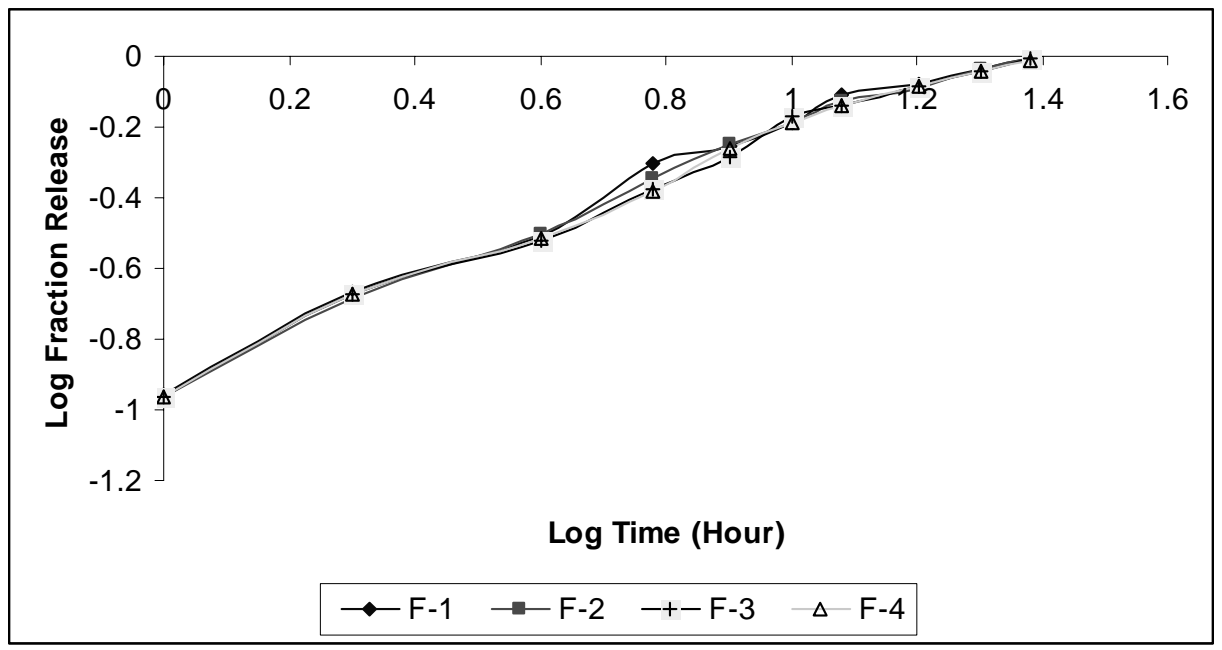

Figure 4. Korsmeyer plot of release kinetics of aceclofenac SR tablet 


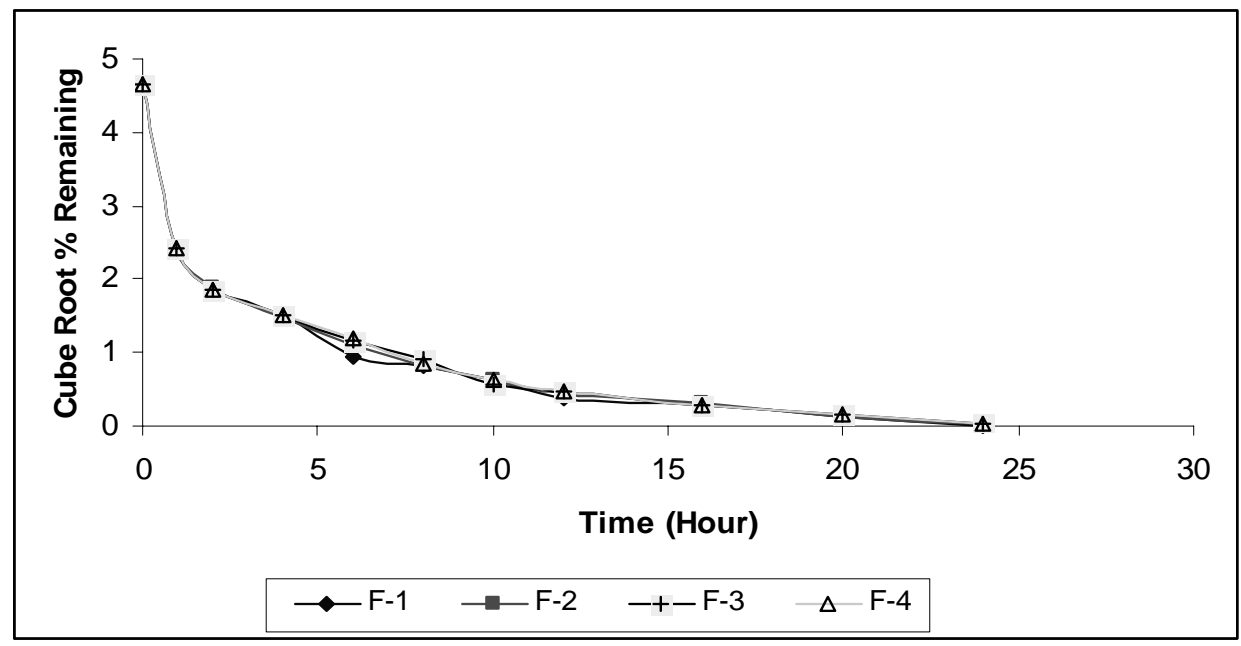

Figure 5. Hixson-Crowell plot of release kinetics of aceclofenac SR tablets

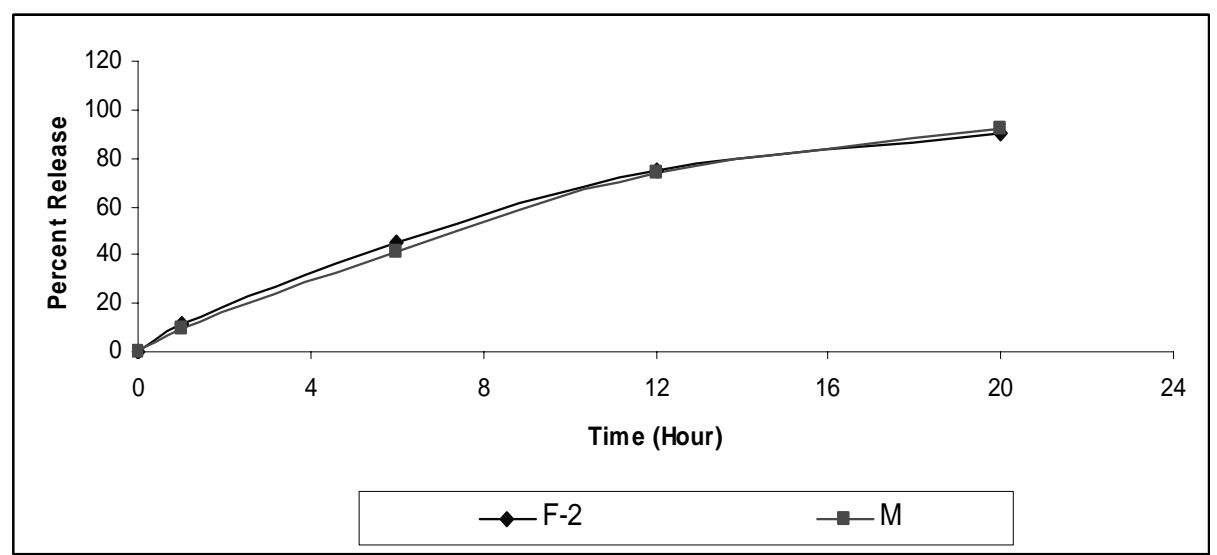

Figure 6. Comparison of release kinetics of F-2 and commercial brand Arrestin SR (M)

was found among different batches of the tablets, and the percentage of drug content was more than $96 \%$. In this study, the percentage friability for all the formulations was below $1 \%$, indicating that the friability was within the official limits. ${ }^{7,89}$ All the tablet formulations showed acceptable pharmacotechnical properties and complied with the in-house specifications for weight variation, drug content, hardness and friability. The proposed formulation F-2 (using 20\% Methocel $\mathrm{K} 15 \mathrm{M}$ and 20\% Methocel K100M) exhibited official drug release than other formulations for $24 \mathrm{~h}$ period. ${ }^{15}$ This drug release pattern was compared with a commercial brand Arrestin SR (Manesh Pharma, India) and found both were similar to each other (Figure 6). Among these formulations, the rate and extent of drug release was decreased with increasing the amount of Methocel. This polymer has been well known to retard the drug release by swelling in aqueous media. ${ }^{10}$ A polymer's ability to retard the drug release rate is related to its viscosity. However, processing factors including particle size, hardness, porosity and compressibility index etc. also affect the release rate of drug from tablets. The hydration rate of HPMC depends on the nature of the substituent like hydroxypropyl group content. Hence, Methocel was used because it forms a strong viscous gel in contact with aqueous media, which may be useful in controlled delivery of drugs. ${ }^{11}$ The drug release data obtained were extrapolated by Zero order, Higuchi, First order, Korsmeyer-Peppas and Hixson-Crowell equations to know the mechanism of drug release from these 
formulations (Table 4). ${ }^{12,13}$ In this experiment, the in vitro release profiles of drug from all these formulations could be best expressed by Higuchi's equation, as the plots showed highest linearity ( $R^{2}$ : 0.97 to 0.99 ). To confirm the diffusion mechanism, the data were fitted into Korsmeyer-Peppas equation (Figure 4). The formulations showed good linearity $\left(R^{2}: 0.97\right.$ to 0.99$)$, with slope (n) values ranging from 0.605 to 0.820 , indicating that diffusion was the predominant mechanism of drug release from these formulations. When plotted according to KorsmeyerPeppas equation, the formulations showed high linearity $\left(\mathrm{R}^{2}: 0.99\right)$, with a comparatively high slope (n) values of $>0.6$, which appears to indicate a coupling of diffusion and erosion mechanisms-so called anomalous diffusion. Hence, diffusion coupled with erosion might be the mechanism for the drug release from Methocel based matrix tablet. The release profile of aceclofenac from all these formulations displayed very poor fitting with HixsonCrowell cube root model of drug release which were related with the method of manufacture followed (Figure 5). ${ }^{14}$

\section{CONCLUSION}

In order to achieve patient compliance for the management of different types of pain, formulation of once daily aceclofenac matrix tablet is essential. This matrix promotes desired controlled drug release upon hydration, swelling and gel formation when interact with gastrointestinal fluid. Methocel based formulation F-2 where 1:1 ratio of Methocel K15M and $\mathrm{K} 100 \mathrm{M}$ used, fulfilled the official release order and comparable with commercial brand Arrestin SR (Figure 6). Thus, the proposed formulation F-2 can be successfully used for commercial production because it was stable under accelerated stability condition.

\section{REFERENCES}

1. Mutalik, S., Naha, A., Usha, A.N. and Ranjith, A.K. 2007. Preparation, In vitro, preclinical and clinical evaluations of once daily sustained release tablets of aceclofenac. Arch Pharm. Res. 30, 222-234.

2. British Pharmacopoeia. 2005. The Stationary office, MHRA, British Pharmacopoeial Commission office, London. 1.

3. Reddy, R.K., Mutalik, S. and Reddy, S. 2003. Once daily sustained release matrix tablets of Nicorandil: formulation and in vitro evaluation. AAPS. Pharm. Sci. Tech. 4, 61.

4. Ford, J.L., Rubinstein, M.H. and Hogan, J.E. 1987. Study on controlled drug release kinetics from hydrophilic matrices. Int. J. Pharm. 40, 223 -234.

5. Ford, J.L., Rubinstein, M.H. and Hogan, J.E. 1985. Formulation of sustained-release promethazine hydrochloride tablets using hydroxypropyl methyl cellulose matrixes. Int. J. Pharm. 24, 327-338.

6. Vazquez, M.J., Perez-Marco, Gomez-Amoza, J.L., MartinezPacheco, R., Souto, C. and Concheiro. A. 1992. Influence of technological variables on drug release of drug from hydrophilic matrices. Drug Dev Ind Pharm. 18, 1355-1375.

7. Aulton, M.E. and Wells, T.I. 1998. Pharmaceutics: The Science of Dosage Form Design. London, England, Churchill Livingstone.

8. Liebermann, H.A., Lachman, L. and Schwartz, J.B. 2001. Pharmaceutical Dosage Forms: Tablets. Marcel Dekker, New York, pp 201-243.

9. Martin, A. 2001. Micromeritics. In: Martin A, ed, Physical pharmacy. Baltimore, MD: Lippincott Williams and Wilkins; pp. $423-454$.

10. Michailova, V., Titeva, S., Kotsilkova, R., Krusteva, E. and Minkov. E. 2000. Water uptake and relaxation process in mixed unlimited swelling hydrogels. Int. J. Pharm. 209, 4546.

11. Hogan, J.E. 1989. Hydroxypropylmethylcellulose sustained release technology. Drug Dev Ind Pharm. 15, 975-999.

12. Higuchi, T. 1961. Mechanism of sustained action medication, Theretical analysis of rate of release of solid drugs dispersed in solid matrices, J. Pharm. Sci. 52, 11451149 .

13. Korsmeyer, R.W, Gurny, R., Doelker, E.M., Buri, P. and Peppas, N.A. 1983. Mechanism of solute release from porous hydrophilic polymers. Int.. J. Pharm.. 15, 25-35.

14. Kabir, A.K.L, Hussain, M.M., Biswas, B.K. and Rouf, A.S.S.R. 2008. Formation 2 In vitro evaluation of theophylline sustained release tablet from hydrophilic matrix. J. Ch. Pharm. Sci. 1, 74-78.

15. United States Pharmacopoeia 29th Edition, NF 24, 2006. 